\title{
A High Frequency (HF) Inductive Power Transfer Circuit for High Temperature Applications Using SiC Schottky Diodes
}

\author{
Jennifer L. Jordan, George E. Ponchak, David J. Spry and Philip G. Neudeck \\ NASA Glenn Research Center, 21000 Brookpark Rd., MS 77/1, Cleveland, OH 44135
}

\begin{abstract}
Wireless sensors placed in high temperature environments, such as aircraft engines, are desirable to reduce the mass and complexity of routing wires. While communication with the sensors is straight forward, providing power wirelessly is still a challenge. This paper introduces an inductive wireless power transfer circuit incorporating $\mathrm{SiC}$ Schottky diodes and its operation from room temperature $\left(25^{\circ} \mathrm{C}\right)$ to $500{ }^{\circ} \mathrm{C}$.
\end{abstract}

Index Terms - High Temperature, Inductive Power Transfer, SiC Diode.

\section{INTRODUCTION}

There is an increasing interest in sensors that can operate in high temperature environments, for example, in aircraft engines, oil and gas exploration, mining and automobiles. Besides the obvious use of RFIDs, active sensors have been powered by wires, thus eliminating the advantages of "wireless" sensors [1]. Inductive, through wall power transfer is an ideal application for harsh environments, with the transmitting coil outside the chamber and the inductive power sensor inside the harsh environment chamber [2]. Wide bandgap semiconductor diodes will be needed for high temperature wireless or inductive power transfer.

$\mathrm{SiC} p n$ diode rectifiers have been demonstrated with excellent results through $500{ }^{\circ} \mathrm{C}$, but the rectifiers were only demonstrated at $10 \mathrm{~Hz}$ [3]. It is not clear if this was a limitation of the diodes or simply the chosen frequency to demonstrate the rectifier. SiC diodes were used to demonstrate a $2.45 \mathrm{GHz}$ rectenna that operated through $300{ }^{\circ} \mathrm{C}$, but those diodes were not optimized for high temperature and the demonstrated efficiency was low [4].

In this paper, $\mathrm{SiC}$ diodes designed for operation at high temperature are used to demonstrate an inductive power transfer circuit.

\section{EXPERIMENTAL PROCEDURE}

The receiving circuit comprised of the pickup coil and rectifier were fabricated on a $0.508 \mathrm{~mm}$ thick alumina substrate. A schematic and a photograph of the circuit are shown in Figs. 1 and 2, respectively. The pickup coil is a two-turn coil with $1.5 \mathrm{~mm}$ wide traces and $1.25 \mathrm{~mm}$ wide spacing; the outer turn is 40 by $40 \mathrm{~mm}$. The low pass filter is comprised of an LC pi network with MACOM MA4M3050 50 pF capacitors and a Piconics SP12P5-61AE $100 \mathrm{nH}$ inductor. The filter was designed for an $80 \mathrm{MHz}$ corner frequency, but because the circuit was ultimately characterized at $10 \mathrm{MHz}$, the filter had no effect on the rectifier. A MACOM MA4M3150 $150 \mathrm{pF}$ capacitor was used at the output for the DC-pass filter. Because the ultimate application is to provide biasing for transistors, such as in the pressure sensor circuit of [1], a high resistance load was used; the load resistor $\left(R_{L}\right)$ is a $10 \mathrm{k} \Omega$, $0.125 \mathrm{~W}$ Mini-Systems chip resistor.

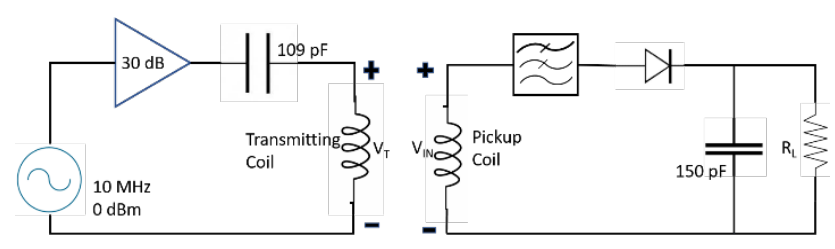

Figure 1: Schematic of inductive power transfer circuit.

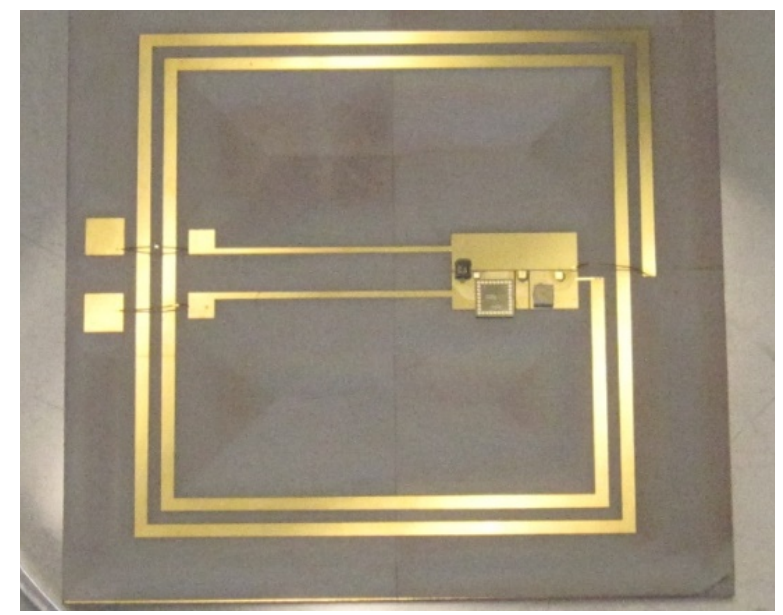

Figure 2: Photograph of pickup coil and rectifying circuit.

The 4H-SiC Schottky diode cross-section shown in Fig. 3 was fabricated at NASA GRC using the Iridium Interface Stack (IrIS) metalization [5] that has previously demonstrated thousands of hours electrical operation at $500{ }^{\circ} \mathrm{C}$ as the bond pads for $4 \mathrm{H}-\mathrm{SiC}$ JFET integrated circuits [6]. For the top side contact, $\mathrm{TaSi}_{2}$ metal is in contact with the semiconductor, while the back-side contact had a $100 \mathrm{~nm}$ thick titanium layer in addition to the $\mathrm{TaSi}_{2} / \mathrm{Pt} / \mathrm{Ir} / \mathrm{Pt}$ metal. Normally, current flow is dictated by the rectifying small-area $\mathrm{TaSi}_{2}$ Schottky contact anode to the lightly-doped epilayer, with current flowing through the conductive substrate and large-area backside contact. To reduce the electric field crowding around the metal- 
semiconductor contact periphery, the Schottky contact overlaps a via with a compound beveled sidewall produced by wet $\mathrm{BOE}$ etching through field passivation oxide comprised of $\sim 50 \mathrm{~nm} 1150{ }^{\circ} \mathrm{C}$ wet thermal oxide followed by $1 \mu \mathrm{m}$ of low pressure chemical vapor deposition

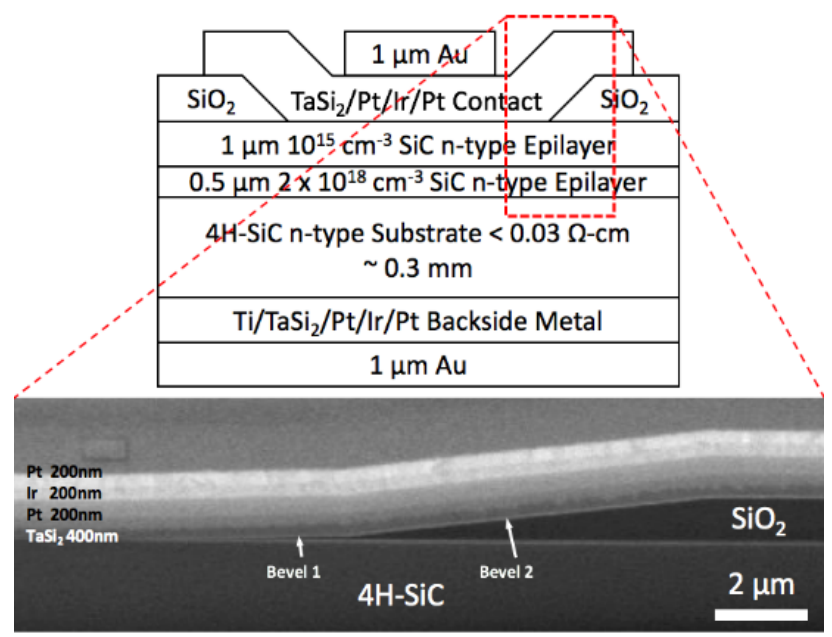

Figure 3: Simplified cross-sectional schematic of fabricated $4 \mathrm{H}-$ SiC Schottky diode with corresponding focused ion beam (FIB) cut field emission scanning electron microscope (FE-SEM) crosssectional image.

(LPCVD) deposited oxide using tetraethyl orthosilicate (TEOS) at $720^{\circ} \mathrm{C}$.

Prior to dicing, all devices were DC characterized at $25^{\circ} \mathrm{C}$ on an automated probing station. The differential series resistance $\mathrm{R}_{\text {Diff }}=\mathrm{dI} / \mathrm{dV}$ measured at $1.9 \mathrm{~V}$ forward bias was $6.9 \pm 0.9 \Omega$. The wafer was then diced and selected $3 \times 3 \mathrm{~mm}$ die were mounted for high temperature DC measurements.

Post-dicing DC measurements were conducted separately in an oven on selected die mounted in a hightemperature ceramic package [7]. Diodes were I-V measured at selected temperatures during ramp from $25^{\circ} \mathrm{C}$ to $500{ }^{\circ} \mathrm{C}$ (at $\leq 3{ }^{\circ} \mathrm{C} / \mathrm{min}$ rate), during the 640 hour hold at $500{ }^{\circ} \mathrm{C}$, and during ramp down back to $25^{\circ} \mathrm{C}$. Fig. 4 compares DC I-V characteristics measured at 25, 300, and $500{ }^{\circ} \mathrm{C}$ on a representative device during temperature ramp up and temperature ramp down on a logarithmic current scale. The IrIS contact $500{ }^{\circ} \mathrm{C}$ durability is re-confirmed by minimal change in $\mathrm{I}-\mathrm{V}$ characteristics before and after 640 hours at $500{ }^{\circ} \mathrm{C}$. While reverse-bias leakage is increased by many orders of magnitude at $500{ }^{\circ} \mathrm{C}$, the rectification ratio (of on-state current at $1.9 \mathrm{~V}$ to off-state current at $-20 \mathrm{~V}$ ) remains above 30.

Fig. 5 details the temperature-dependence of the forward I-V characteristics on a linear current scale. For this plot, $25{ }^{\circ} \mathrm{C}$ probe-test $\mathrm{I}-\mathrm{V}$ data from the same device is included (black solid line) and reveals an important discrepancy compared to $25{ }^{\circ} \mathrm{C} \mathrm{I-V}$ measured after packaging (black dashed line) on the same diode. We attribute this major prevs. post-packaging discrepancy in high-current conduction to non-ideal conduction through backside contact, the area of which drops by a factor of $\sim 500$ after dicing compared to whole-wafer probing. As temperature exceeds $\sim 200{ }^{\circ} \mathrm{C}$, the backside contact conduction increases sufficiently that high-current flow becomes dictated by the small-area Schottky diode epilayer resistance. Fig. 6 plots the differential series resistance, $\mathrm{dI} / \mathrm{dV}$, extracted from Fig. 5 forward I-Vs at applied voltage of $1.9 \mathrm{~V}$. Above $200{ }^{\circ} \mathrm{C}$, the diode differential series resistance increases consistently with understood unipolar conduction behavior of lightlydoped epilayer $4 \mathrm{H}-\mathrm{SiC}$ Schottky diodes.

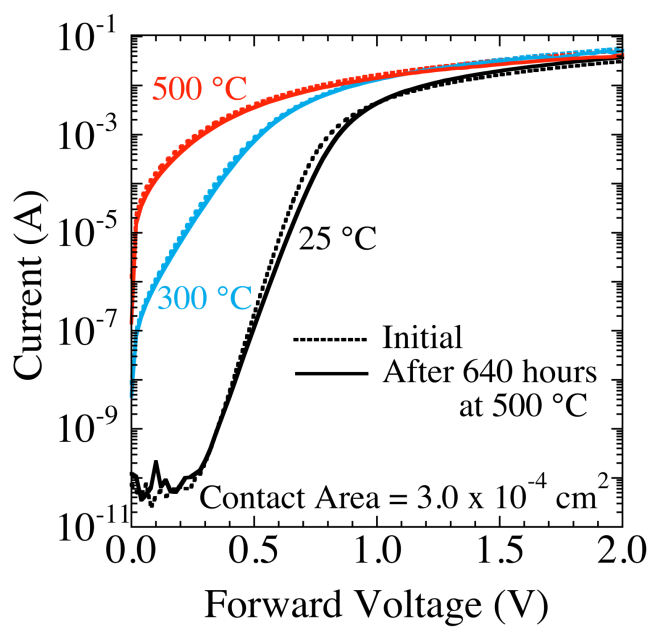

(a)

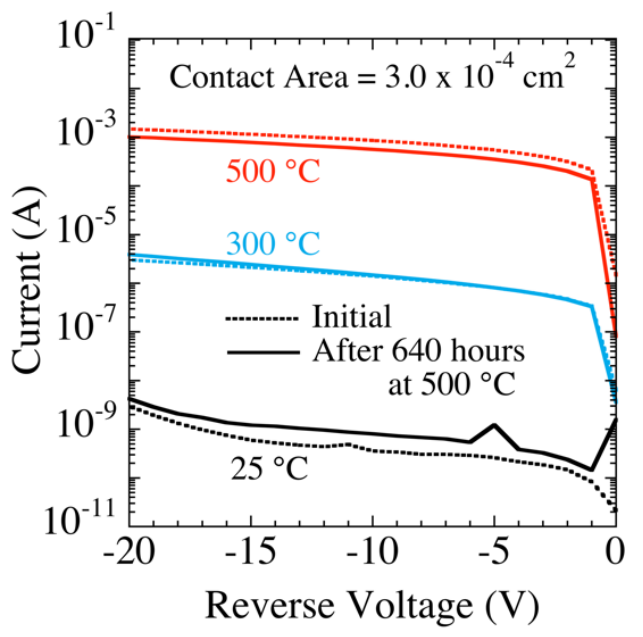

(b)

Figure 4: Representative SiC diode (a) forward and (b) reverse $\mathrm{I}-\mathrm{V}$ characteristics at selected temperatures before (dashed) and after (solid) 640 hours in a $500{ }^{\circ} \mathrm{C}$ oven. 


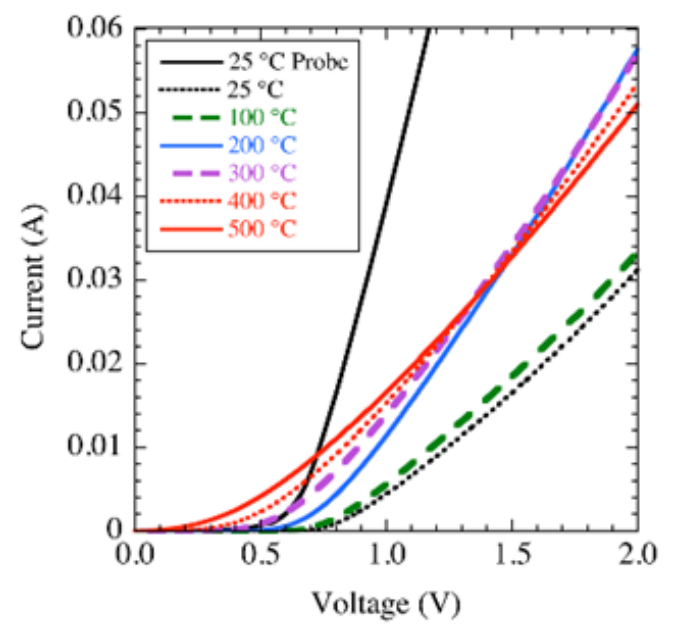

Figure 5: Linear current scale forward I-V characteristics at selected temperatures (from same device in Figure 4). Large difference between $25^{\circ} \mathrm{C}$ probe-tested (black solid) vs. packagetested (black dashed) is attributed to non-ideal backside contact.

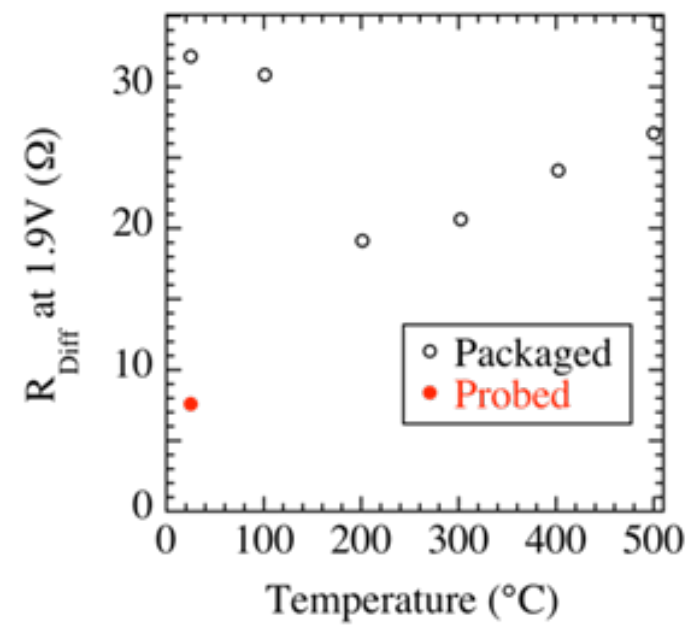

Figure 6: Differential diode on-resistance $\mathrm{dI} / \mathrm{dV}$ at $1.9 \mathrm{~V}$ applied diode voltage vs. temperature (extracted from Fig. 5 representative device $\mathrm{I}-\mathrm{V}$ data).

A photograph of the inductive power transfer test setup is shown in Fig. 7 and schematically in Fig. 1. The transmitting coil is a nine-turn wire coil wrapped around the Shuttle tile forming a 15 by $11 \mathrm{~cm}$ rectangular coil. The transmitting coil is approximately $1 \mathrm{~cm}$ below the pickup coil and rectifier. A ceramic heater is secured to the top of the Shuttle tile and a thermocouple measures the temperature on top of the rectifier circuit. DC needle probes pick up the output voltage, and an Agilent multimeter is used to measure the output. The power measured after the amplifier is $25.5 \mathrm{dBm}$. The voltage, as measured on an oscilloscope, is $37 \mathrm{~V}$ peak-to-peak across the transmitting coil $\left(\mathrm{V}_{\mathrm{T}}\right)$. A pickup coil, without the rectifier circuit, was fabricated and used to measure the voltage $\left(\mathrm{V}_{\mathrm{IN}}\right)$ to the rectifier; it is $3 \mathrm{~V}$ peak-to-peak.

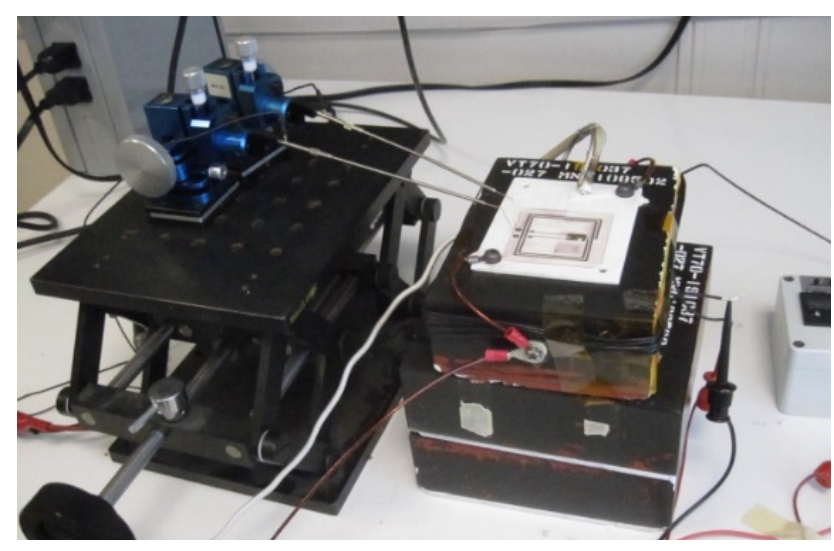

Figure 7: Photograph of test setup. Note the ceramic heater on the Shuttle tile thermal insulation blocks.

\section{MEASURED RESUltS}

The measured DC voltage is shown in Fig. 8 with two definitions of voltage conversion efficiency. The first efficiency is defined as the DC voltage to the transmitted voltage, or

$\eta_{T}=\frac{V_{D C}}{V_{T, p e a k} / \sqrt{2}}$.

And the second efficiency is defined as the DC voltage to the received voltage by the pickup coil, or

$\eta_{I N}=\frac{V_{D C}}{V_{I N, \text { peak }} / \sqrt{2}}$,

$\eta_{\text {IN }}$ is reasonable for a diode designed and manufactured to survive high temperatures and not necessarily optimized for use in a wireless power transfer circuit. $\eta_{\mathrm{T}}$ is low, but this can be improved by using a larger pickup coil or smaller transmitting coil. Note that in the current design, the area of the pickup coil is only $\sim 10 \%$ of the transmitting coil so the coupled magnetic flux is low. Finally, note that the DC voltage and efficiency is maximum around $200^{\circ} \mathrm{C}$, which corresponds to the minimum in diode resistance, as shown in Fig. 6.

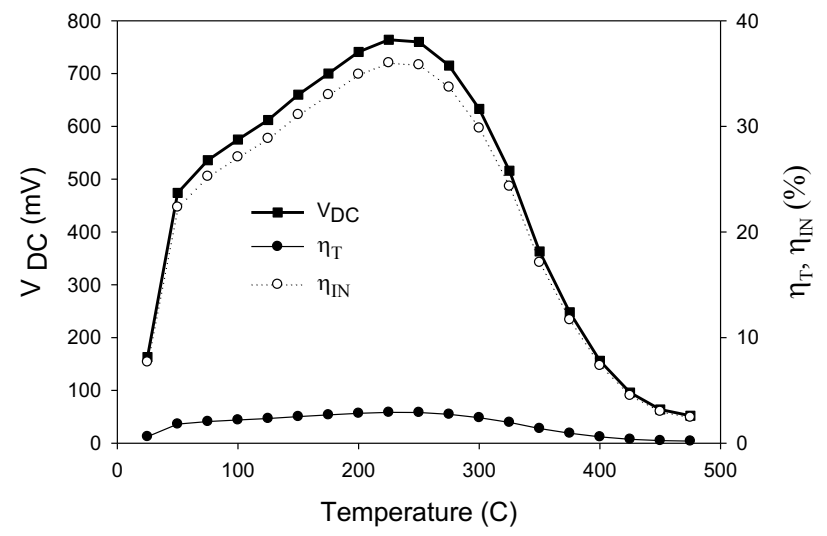

Figure 8: Measured $\mathrm{V}_{\mathrm{DC}}$ and efficiency. 


\section{CONCLUSION}

An inductive power transfer circuit is demonstrated using $4 \mathrm{GH}-\mathrm{SiC}$ Schottky diodes that operate reliably at $500^{\circ} \mathrm{C}$. Further work should improve the diode performance, particularly at lower temperatures, with implementation of improved backside contact. Also, improvements in the inductive power transfer circuit may be made to increase the voltage efficiency.

\section{ACKNOWLEDGEMENT}

This work was supported by the NASA Glenn Research Center Center Innovation Fund.

\section{REFERENCES}

[1] M. C. Scardelletti, J. L. Jordan, R. D. Meredith, K. Harsh, E. Pilant, M. W. Ursey, G. M. Beheim, G. W. Hunter, and C. Zorman, "Demonstration of a Packaged Capacitive Pressure Sensor System Suitable for Jet Turbofan Engine Health Monitoring," In $66^{\text {th }}$ IEEE Electronic Components and Technology Conference (ECTC), pp. 877-888.
[2] A. Hassan, A. Trigui, U. Shafique, Y. Savaria, and M. Sawan, "Wireless power transfer through metallic barriers enclosing a harsh environment; feasibility and preliminary results," In 2016 IEEE International Symposium on Circuits and Systems (ISCAS), pp. 2391-2394.

[3] S. Shao, W.-C. Lien, A. Maralani and A. P. Pisano, "Integrated $4 \mathrm{H}$-silicon carbide diode bridge rectifier for high temperature (773 K) environment," In IEEE 44th European Solid State Device Research Conference (ESSDERC), 2014 , pp. 138-141.

[4] Z. D. Schwartz, G. E. Ponchak, J. L. Jordan and A. N. Downey, "2.45 GHz rectenna designed for wireless sensors operating at high temperatures," IMAPS Int. High Temperature Electronics Conf. (HiTEC 2004) Dig., Santa Fe, NM, May 18-20, 2004.

[5] D. J. Spry, U.S. Patent 9,013,002 for "Iridium Interfacial Stack (IRIS)."

[6] D. J. Spry, P. G. Neudeck, L. Chen, D. Lukco, C. W. Chang, and G. M. Beheim, "Prolonged $500^{\circ} \mathrm{C}$ Demonstration of $4 \mathrm{H}-$ SiC JFET ICs with Two-Level Interconnect," IEEE Electron Device Lett., vol. 37, no. 5, pp. 625-628, May 2016. DOI: 10.1109/LED.2016.2544700, [Online].

[7] L. Chen, P. G. Neudeck, D. J. Spry, G. M. Beheim, and G. W. Hunter. (2016, June). Electrical Performance of a High Temperature 32-I/O HTCC Alumina Package. Presented at IMAPS Int. Conf. High Temperature Electronics. [Online]. Available: http://dx.doi.org/10.4071/2016-HITEC-6 